\title{
The Effectiveness of Back Pressure in Superplastic Blow Forming of Aluminum Alloy AA 5083 Performed at Very Favorable Conditions for Cavitation Growth
}

\author{
André Ferrara Carunchio ${ }^{a}$, Daniel Almeida Pereira ${ }^{a, b}$, \\ Mario Henrique Fernandes Batalha ${ }^{a}$, Hugo Borelli Resende ${ }^{a}$, André da Silva Antunes ${ }^{b *}$ \\ anstituto de Pesquisas Tecnológicas - IPT, 12210-131, São José dos Campos, SP, Brasil \\ ${ }^{b}$ Instituto Tecnológico de Aeronáutica - ITA, 12228-900, São José dos Campos, SP, Brasil
}

Received: April 09, 2018; Accepted: June 25, 2018

\begin{abstract}
Many components for aerospace and automotive industries are currently manufactured using superplastic forming, being the fine-grained aluminum alloy AA5083 widely used for this proposes. However, the development of cavitation voids is inherent in this process and reduces the ductility of the alloy. Back pressure can be used to diminish the growth of cavitation void. The experimental conditions used in this work are in the best condition for nucleation and grow of cavitation, because of the coarse grain size $(81 \mu \mathrm{m})$, large second phase particles $(9 \mu \mathrm{m})$ and elevated test temperature $\left(570^{\circ} \mathrm{C}\right)$ in a AA 5083. Domes were formed at $570^{\circ} \mathrm{C}$ and at a strain rate of $5 \times 10^{-5} \mathrm{~s}^{-1}$ by blow forming with and without back-pressure. They were compared in terms of their final shape, thickness distribution, and quantity of cavitation voids. The effectiveness of the usage of back pressure to reducing the quantity of cavitation void was analyzed.
\end{abstract}

Keywords: Superplastic Blow Forming, Back pressure, Cavitation, Aluminum 5083, Lightweight Structures.

\section{Introduction}

The superplasticity can be defined as: "...the deformation process that produces essentially neck-free elongations of many hundreds of percent in metallic materials deformed in tension". Elongations of 200-500 \% are quite common, but an extraordinary $5500 \%$ elongation can be found in aluminum bronze alloys ${ }^{2}$. The superplasticity has been employed for more than fifty years by industry ${ }^{3}$, complex shaped pieces produced by superplastic blow forming are used by aerospace and automotive industry ${ }^{3-6}$.

The tensile stress, in the superplastic materials, is sensitive to change in the strain rate. It diminishes the necking because the strain rate and consequently the tensile stress in the neck region are higher than at surround regions ${ }^{1-7}$. The parameter that expresses the capability of the superplastic materials in resisting the necking formation is the strain rate sensitivity parameter, $m$, defined by the equation $\ln (\Delta \sigma) / \ln (\Delta \dot{\varepsilon})^{1}$, in with the $\Delta \sigma$ is the tensile stress variation caused by a change in the strain rate, $\Delta \dot{\varepsilon}$.

There is no onset temperature for superplasticity, so there is a gradual change from plastic (wherein the $m$ is equal to zero) to superplastic deformation (wherein the $m$ is typical above 0.4$)^{1}$. The dominant mechanism of superplastic deformation is grain boundary sliding (GBS) rather than dislocation slip (DS), which are conditioned on the grain size. The grain size can be classified as: Coarse Grain (CG) if the average grain diameter, $d$, is above $10 \mu \mathrm{m}$; Fine Grain
(FG) if $d$ is between 1 and $10 \mu \mathrm{m}$; and Ultrafine-grain (UFG) if $d$ is between $100 \mathrm{~nm}$ and $1 \mu \mathrm{m}^{9,10}$. The superplasticity usually requires $\mathrm{FG}$ materials.

Superplastic blow forming is a manufacturing technique that consists in applying gas pressure in one or more sheets against a female die, resulting in a formed part similar to the die geometry. The possibility of manufacturing complex geometry, lightweight, and strong thin-shell parts makes this process a desirable technique to be applied in industries such as aeronautical, automobile, medical and many others, being possible to reduce or even avoid the need for heavy machining and assembly processes, such as riveting and welding, which is expensive and time-consuming ${ }^{7}$. Simplified analytical analysis such as Dutta and Mukherjee ${ }^{11}$ could be used to obtain pressure-time relationship for domes required to keep the material in the optimal range of strain rate for superplasticity.

Cavitation is a phenomenon that generates voids during superplastic deformation. It happens due to loss of cohesion of the grains caused principally by the presence of hard second phase particles ${ }^{1}$. The excess of cavitation void can promote premature fracture by growth and interlinkage of cavitation void. It results in a relatively low ductility even if the material presents good resistance to necking. The back pressure is applied in the opposite direction of sheet forming. The triaxial stress generated by the back pressure acts by moving the grains into the nucleated cavitation voids, this hinders cavitation growth ${ }^{12}$. 
The aluminum alloy AA 5083 has high mechanical properties, good corrosion resistance, and weldability. It is applied in the automotive and aerospace industry for structural applications. In that context, the AA 5083 SPF alloy was specially developed for industrial application in the manufacturing of components by superplastic blow forming, which presents the superplastic characteristics: ductility of $340 \%$ at a temperature of $550^{\circ} \mathrm{C}$ and strain rate of $1 \times 10^{-3} \mathrm{~s}^{-1}$ with a grain size of $5.6 \mu \mathrm{m}^{13}$.

The AA 5083 has manganese-iron-based primary precipitates particles. These second phase particles have the function of pinning the grain boundary restricting the grain grow during superplastic forming. However, the alloy presents an excessive quantity of cavitation voids nucleated principally in these particles. The larger the size of hard second phase particles, the greater the number of cavitation voids. The particles size is usually around 1.3 $\mu \mathrm{m}$, to minimize the cavitation void formation ${ }^{13}$. Besides that, the nucleation of cavities increases with grain size ${ }^{14}$. However, back pressure can be applied in the superplastic blow forming process to minimize the void formation. It is possible to increase the ductility from 480 to $671 \%$ applying a back pressure of $5.5 \mathrm{bar}^{15}$.

The experimental conditions, used in the present study, are adequate for nucleation and grow of cavitation, because the material analyzed presents coarse grain size $(81 \mu \mathrm{m})$, large second phase particles $(9 \mu \mathrm{m})$ and was tested at elevated temperature $\left(570^{\circ} \mathrm{C}\right)$. The objectives of this paper are to show the deleterious effect of the cavitation in the ductility and the effectiveness of the application of back pressure to solve this problem.

\section{Experimental Procedure}

The as-received sheet was an AA 5083-O aluminum alloy with $6.35 \mathrm{~mm}$ of thickness. The chemical composition was measured by Spark Optical Emission Spectroscopy (S-OES). Samples were mechanically polished using standard metallographic procedure and chemically etched with $\mathrm{HF}$ and $\mathrm{H}_{2} \mathrm{O}$ (2:100) for few seconds, chemical etching and polishing (with colloidal silica) was performed several times until grain boundary revelation. The microstructure was examined by Optical Microscopy (OM) and Scanning Electron Microscopy (SEM) and large second-phase particles were analyzed by energy-dispersive X-ray spectroscopy (EDX). The second-phase particles were quantified using the software ImageJ. The grain size was measured by the line intercept method, five OM images with six lines per image were used - three at longitudinal and three at transversal.

The strain rate sensitivity parameter " $\mathrm{m}$ " was determined using change in strain-rate method usually named as step test. The tensile test until fracture was conducted at increasing speed to maintain a constant strain rate. A universal testing machine (INSTRON 5500R) with the furnace at temperature equals to $570^{\circ} \mathrm{C}$ was used. Machined dog-bone specimens (gauge length of $25 \mathrm{~mm}$ ) were used. The surface fracture and the longitudinal section of the tensile tested specimens were analyzed in the SEM above mentioned. The SEM images from longitudinal section were processed, using digital image processing software ImageJ, to determine the area fraction of cavitation void, sample surface was left unetched to facilitate the threshold processing between the voids and the specimen surface.

The machine used in the experimental procedures, presented in Figure 1, works with a system range of 15 to 150 Ton of hydraulic clamp force and has a work area of approximately $760 \times 860 \mathrm{~mm}$. The gas pressure, which presses the blank against the die, has a range of 1 to 40 bar and can work with gas injection in both sides of the blank (a necessary condition for any work using back pressure). The control system allows different values of pressure, ramp gas rate, dwell time and clamp force during the forming process, what should be specified according to final part geometry and material. The Dutta and Mukherjee quantitative analysis ${ }^{11}$ was used to obtain pressure-time relationship required to keep the material at constant strain rate. A dome-shaped die with $180 \mathrm{~mm}$ in diameter was used. Two blow formed domes were produced at $570^{\circ} \mathrm{C}$ and strain rate of $5.0 \times 10^{-4}$ $\mathrm{s}^{-1}$, the back pressure of 10 bar was applied in one of them.

A coordinate system with two dimensions was used to describe the position of the sample on the dome surface: one is the angle from the pole, $\varphi\left(0-90^{\circ}\right)$; and other is the angle

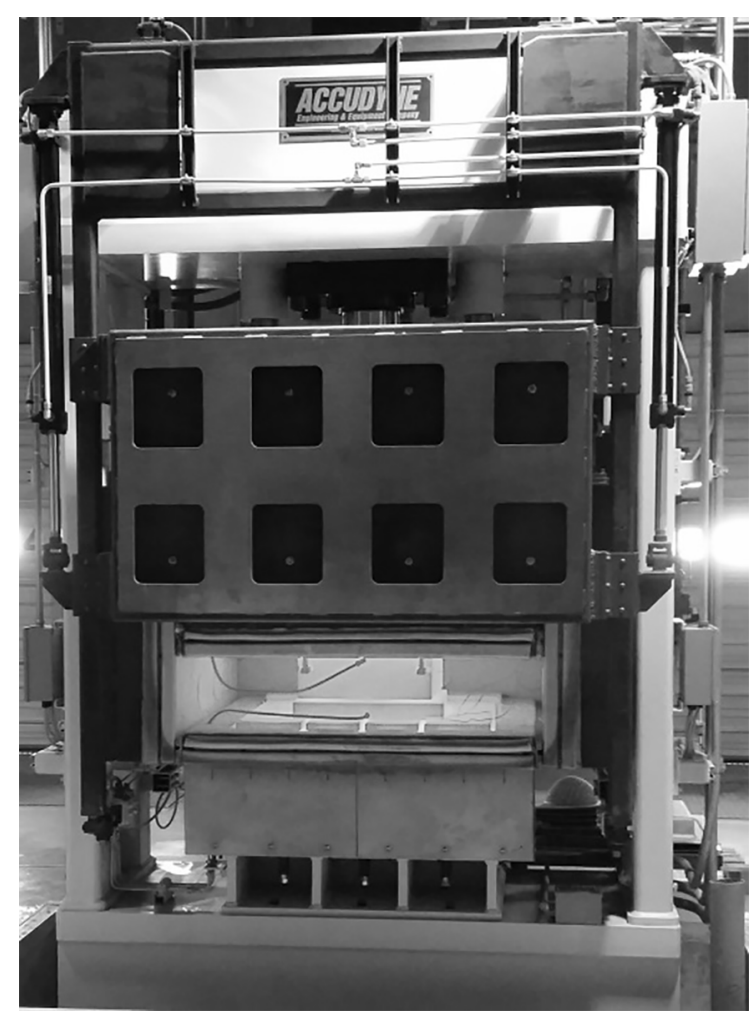

Figure 1. Superplastic forming Accudyne machine used in the work. 
from the rolling direction (RD), $\theta\left(0-90^{\circ}\right)$, as illustrated in Figure 2 . A rotational symmetry of order 4 was assumed.

\section{Results and Discussions}

The composition of the as-received sheet of AA5083-O aluminum alloy is listed in Table 1. The results show that the chemical composition is in accordance with ASTM B209M-14 ${ }^{16}$.

Figure 3 shows the OM image of the as-received sheet of AA5083-O, chemically etched. The grain size of $81.1 \pm 2.6$ $\mu \mathrm{m}$ was measured by the line intercept method, thus, it can be classified as Coarse-Grained (CG). It is well known that the average grain size influences the superplastic properties when the grain size is small - Fine Grained (FG) - the superplastic forming can be performed faster and at lower temperatures ${ }^{1,3}$. However, in the case of CG materials, the superplastic forming had to be performed at elevated temperatures - near to melting pointing - and at lower strain rate.

Figure 4 shows the SEM image of the rolling direction of the as-received sheet. It was possible to identify bright and dark second phase particle. The EDS results show that the bright particles have iron and manganese in their chemical composition and the dark particles have magnesium and silicon. Booth these particles are aligned along the rolling direction (RD). The quantitative analysis of five SEM images shown that the area fraction of magnesium and silicon-based particles was $0.06 \pm 0.02 \%$ and the average diameter was $2.15 \pm 0.04 \mu \mathrm{m}$. The area fraction of iron and manganese-based particles was $1.83 \pm 0.17 \%$ and the average diameter was $9.52 \pm 0.18 \mu \mathrm{m}$. The iron and manganese-based particles have the function of pinning the grain boundaries - Zener pinning. It influences the final grain size after recrystallization and the grain growth during superplastic forming. As smaller

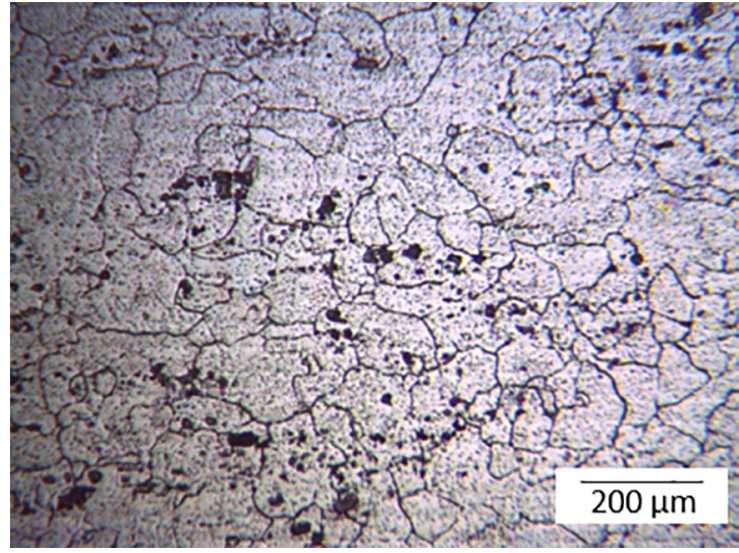

Figure 3. MO image in the rolling direction of the AA5083-O chemical etched, the rolling plane is parallel to the page and the rolling direction is horizontal to the page.

the size of these particles higher pinning action of these particles on the grain boundary ${ }^{7,8}$. On the other hand, second phase particles act as nucleation sites for cavitation void. The size of these particles should be as small as possible to minimize their effects on cavitation phenomenon. The average particle diameter - presented by the analyzed alloy - is very large compared with results in the literature in which a diameter of $1.3 \mu \mathrm{m}$ is recommended to reduce the amount of cavitation void'.

Figure 5 shows step test at $570^{\circ} \mathrm{C}$ of the coarse-grained AA5083-O. The strain rate sensitivity parameter " $m$ " and the parameters for it calculation - obtained from step test are summarized in Table 2 . The $m$ value is very dependent on strain rate, the minimum value was 0.29 at $1.0 \times 10^{-4} \mathrm{~s}^{-1}$ and the maximum was 0.38 at $1.0 \times 10^{-5} \mathrm{~s}^{-1}$, in the analyzed range. The $m$ value of 0.65 was observed in the literature for strain rate of $5.0 \times 10^{-4} \mathrm{~s}^{-1}$ at $565^{\circ} \mathrm{C}$ and with a grain size
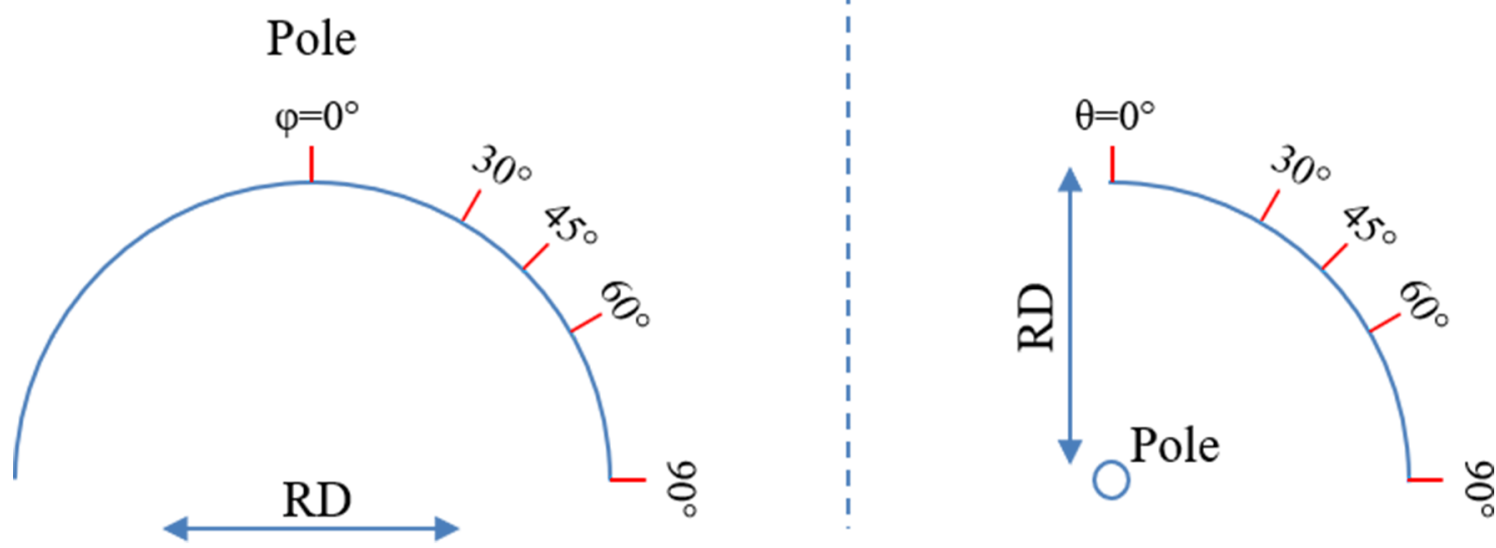

Figure 2. The coordinate system with two dimensions adopted in this work.

Tabela 1. Chemical composition of the as-received sheet AA5083-O aluminum alloy obtained by S-OES.

\begin{tabular}{lcccccc}
\hline $\mathrm{Al} / \mathrm{wt} \%$ & $\mathrm{Mg} / \mathrm{wt} \%$ & $\mathrm{Mn} / \mathrm{wt} \%$ & $\mathrm{Cr} / \mathrm{wt} \%$ & $\mathrm{Si} / \mathrm{wt} \%$ & $\mathrm{Fe} / \mathrm{wt} \%$ & $\mathrm{Cu} / \mathrm{wt} \%$ \\
\hline $94.200 \pm 0.049$ & $4.670 \pm 0.047$ & $0.467 \pm 0.002$ & $0.066 \pm 0.001$ & $0.081 \pm 0.001$ & $0.390 \pm 0.004$ & $0.080 \pm 0.001$ \\
\hline
\end{tabular}




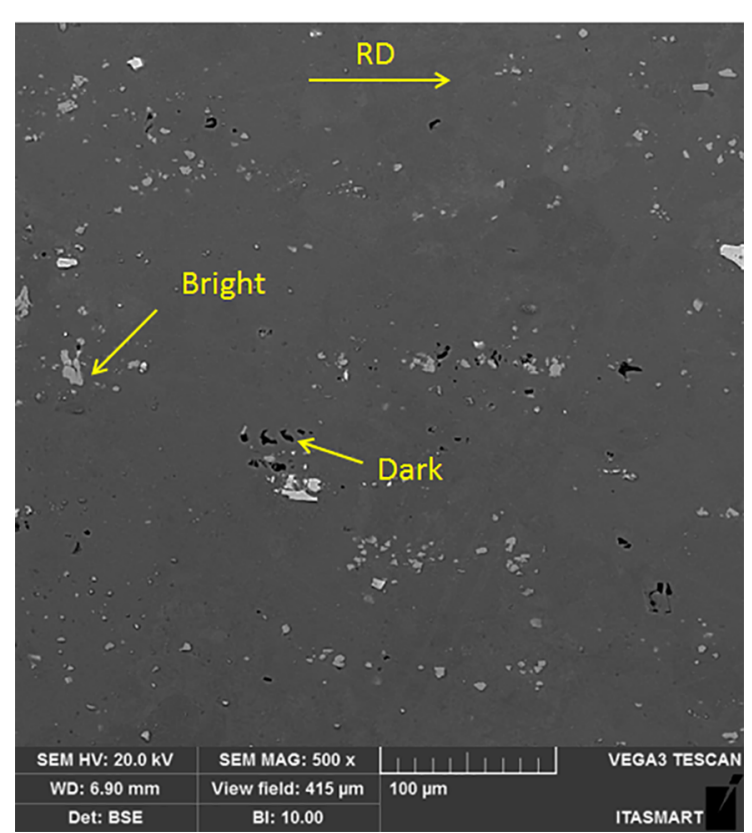

Figure 4. SEM image in the rolling direction of the AA5083-O without chemical etching, the rolling plane is parallel to the page and the rolling direction is horizontal to the page.

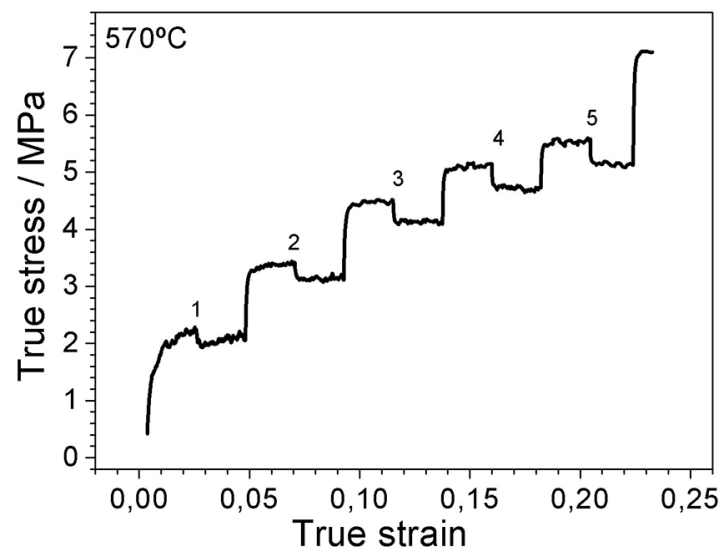

Figure 5. Step test at $570^{\circ} \mathrm{C}$ of the coarse-grained AA5083-O, conditions and results about the steps from 1 to 5 are presented on the Table 2.

Tabela 2. Data from step test of the AA5083-O at test temperature of $570^{\circ} \mathrm{C}$

\begin{tabular}{lccccc}
\hline Step & $\begin{array}{c}\sigma 1 \\
(\mathrm{MPa})\end{array}$ & $\begin{array}{c}\sigma 2 \\
(\mathrm{MPa})\end{array}$ & $\begin{array}{c}\varepsilon 1 \\
\left(\mathrm{~s}^{-1}\right)\end{array}$ & $\begin{array}{c}\varepsilon 2 \\
\left(\mathrm{~s}^{-1}\right)\end{array}$ & $\mathrm{m}$ \\
\hline 1 & 2.26 & 2.05 & $1.0 \times 10-5$ & $7.8 \times 10-6$ & 0.38 \\
2 & 3.40 & 3.13 & $2.5 \times 10-5$ & $2.0 \times 10-5$ & 0.36 \\
3 & 4.46 & 4.12 & $5.0 \times 10-5$ & $4.0 \times 10-5$ & 0.36 \\
4 & 5.11 & 4.74 & $7.6 \times 10-5$ & $5.9 \times 10-5$ & 0.30 \\
5 & 5.52 & 5.15 & $1.0 \times 10-4$ & $7.9 \times 10-5$ & 0.29 \\
\hline
\end{tabular}

of $9 \mu \mathrm{m}^{15}$. The low $m$ value showed is certainly due to the elevated grain size of $81.1 \pm 2.6 \mu \mathrm{m}$.

The rate of $5.0 \times 10^{-5} \mathrm{~s}^{-1}$ was chosen for the blow forming, as it presents the best combination of $m$ value and strain rate. However, the $m$ and the strain rate are lower, and the temperature is higher than the commonly used in superplastic blow forming.

Figure 6 shows the true stress vs. strain rate at $570^{\circ} \mathrm{C}$ of the coarse-grained AA5083-O, the data were extracted from the step test shown in Figure 5. The true stress vs. strain rate could be fitted in a sigmoidal curve. The shape of the curve indicates that, at $5.0 \times 10^{-5} \mathrm{~s}^{-1}$, the alloy is in the region II of deformation at the strain rate chosen. In the region II, the main deformation mechanism is the grain boundary sliding ${ }^{1,4}$. The $m$ can be obtained by the slope of the curve, at this temperature, the alloy presented the value of $m$ near to 0.4 in the region II, as represented in Figure 6.

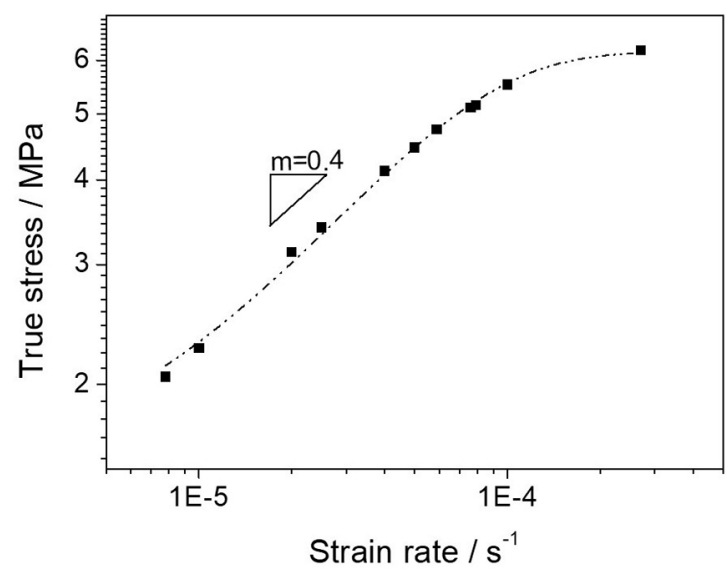

Figure 6. True stress vs. strain rate at $570^{\circ} \mathrm{C}$ of the AA5083-O, the data were extracted from Table 2.

Figure 7 shows the tensile test curve of the AA5083-O performed at a constant strain rate of $5.0 \times 10^{-5} \mathrm{~s}^{-1}$ and temperature of $570^{\circ} \mathrm{C}$. The ultimate true strain was about 0.46 (tensile elongation of $58 \%$ ), this value is very low when compared to the literature that frequently shown an average tensile elongation of $400 \%{ }^{15,17-19}$. The specimens, before and after the tensile test, are presented in Figure 8. Despite the low elongation presented by the specimen, the necking was not the main cause of the failure, as can be observed in Figure $8 \mathrm{~b}$ ). It is suggested that the main reason for this low elongation is by a high amount of cavitation void, as will be discussed below.

Figure 9 shows a SEM image of the fractured tensile specimen shown in Figure $8 \mathrm{~b}$ ). The void, which was near from the fracture area, was formed by interlinkage of neighboring cavitation voids, as indicates by the number of grains inside it. Second phase particles, represented by bright particles, like that shown in Figure 4, on the grains surfaces indicate that the cavitation voids were nucleated at the interfaces 


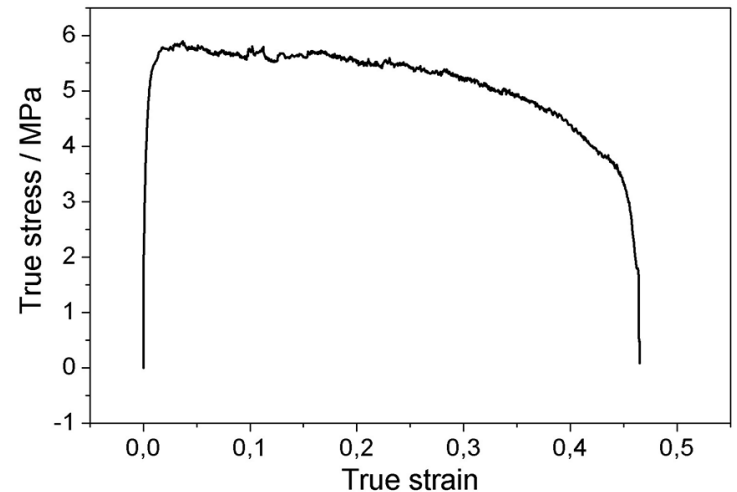

Figure 7. True stress vs. true strain curve of the AA5083-O performed at a constant strain rate of $5.0 \times 10^{-5} \mathrm{~s}^{-1}$ and temperature of $570^{\circ} \mathrm{C}$

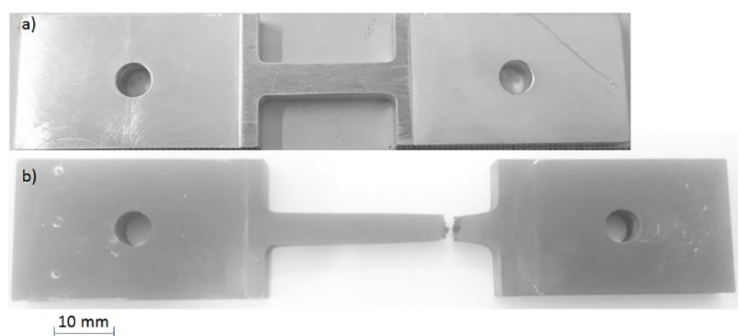

Figure 8. Photography of tensile specimens: a) before and b) after test, the rolling plane is parallel to the page and the rolling direction is horizontal to the page.

between these particles and the grain boundary of the matrix. These observations suggest the fracture happened due to the growth and interlinkage of cavitation voids nucleated at second phase particles.

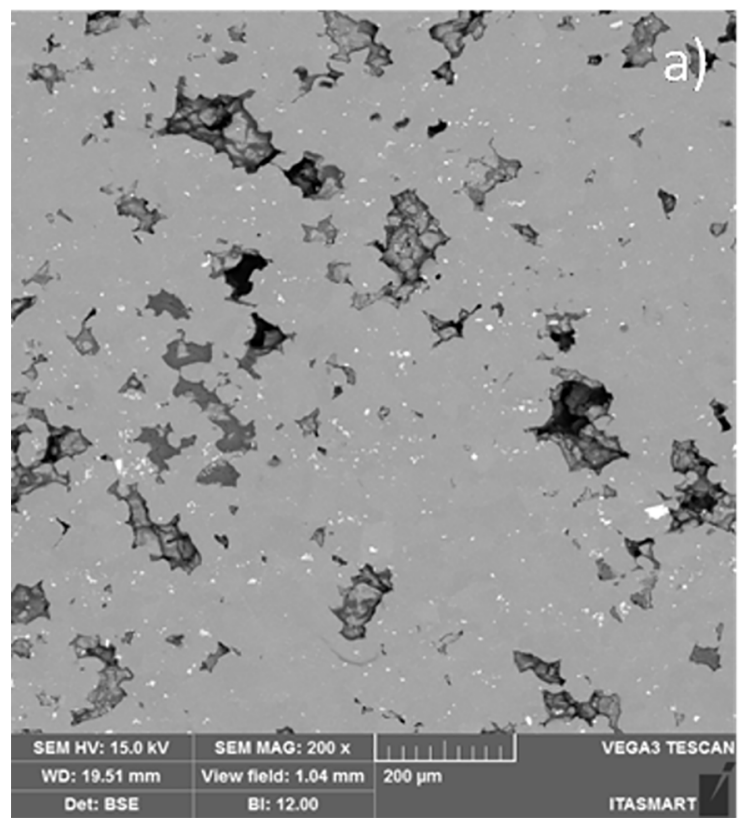

Figure 10. SEM image of the fractured specimen shown in Figure 8 b): a) near to fractured tip; b) at $8 \mathrm{~mm}$ from the fractured tip, the rolling plane is parallel to the page and the rolling direction is horizontal to the page.
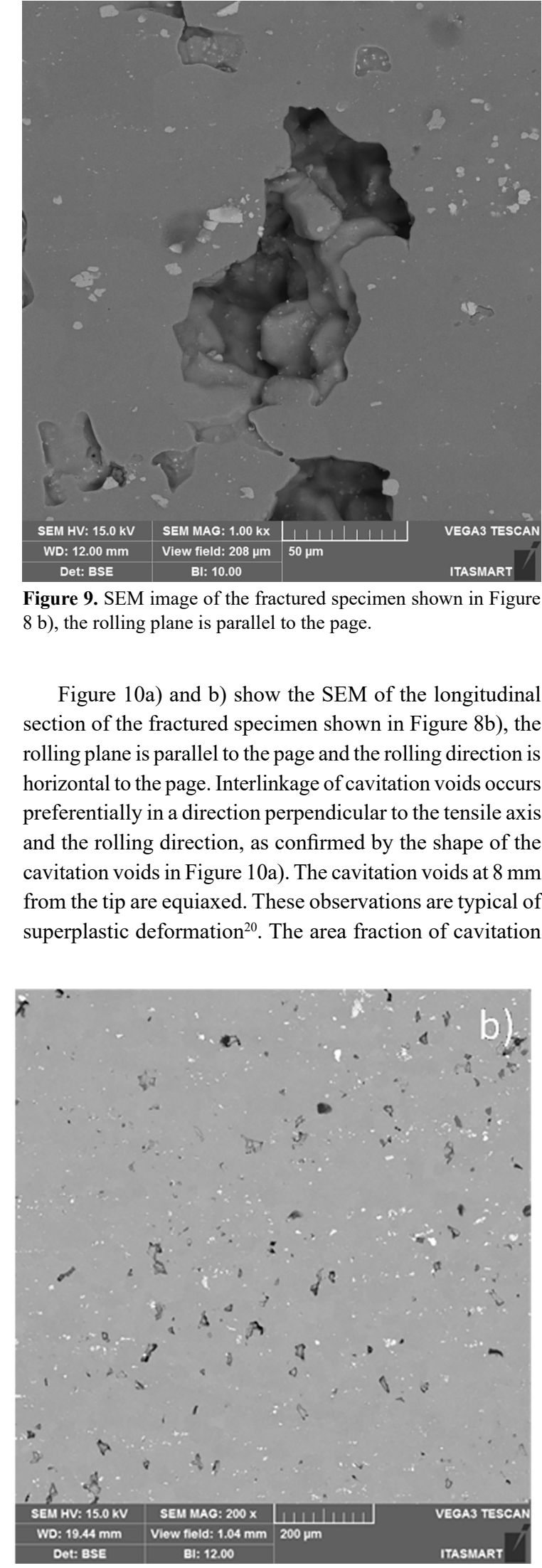

Figure 9. SEM image of the fractured specimen shown in Figure $8 \mathrm{~b}$ ), the rolling plane is parallel to the page.

Figure 10a) and b) show the SEM of the longitudinal section of the fractured specimen shown in Figure 8b), the rolling plane is parallel to the page and the rolling direction is horizontal to the page. Interlinkage of cavitation voids occurs and the rolling direction, as confirmed by the shape of the cavitation voids in Figure 10a). The cavitation voids at $8 \mathrm{~mm}$ from the tip are equiaxed. These observations are typical of superplastic deformation ${ }^{20}$. The area fraction of cavitation preferentially in a direction perpendicular to the tensile axis 
voids along the fractured specimen are presented in Figure 11. The cavitation voids increase with the decreases of the displacement from the tip, it is expected since the quantity of cavitation voids is dependent on the quantity of deformation ${ }^{1}$. The high concentration of cavitation voids in the fracture tip suggests that the fracture occurs due to the interlinkage of cavitation voids. The quantity of cavitation near the fracture tip was about $9 \%$, at 0.45 of true strain, this value is greater than that found in the literature at compatible true strain, as can be seen in Table 3. This is certainly due to the coarse-grained microstructure, large second phase particles and elevated test temperature utilized.

Figure 12 shows the SEM image of the surface fracture of the AA5083-O. It is observed that there are few fibrous ridges and several individual grains, this surface is typical of materials deformed near the region II, as proposed by $\mathrm{SHEN}^{24}$. Several second phase particles can be observed on the surfaces of the grains. This observation suggests that the fracture occurs due to the growth and interlinkage of cavitation voids.

Two domes of AA5083 aluminum alloy were manufactured by SPF in two different conditions: with and without back pressure. In the first procedure, without back pressure, the blank was ruptured during the expansion. The result was a dome with a lower height and fractures at its top, as shown in figure 13 a). The fractures happened inside and outside of

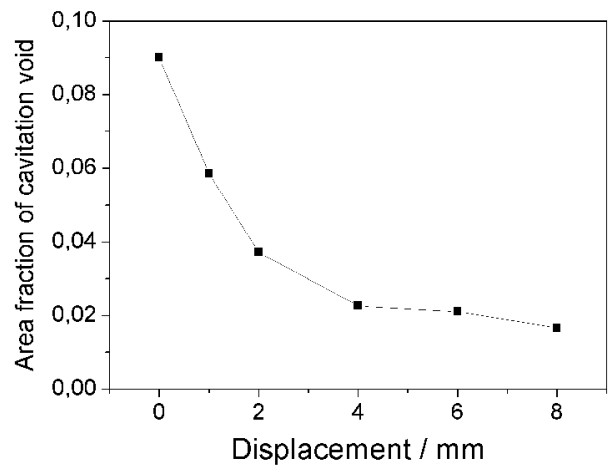

Figure 11. Area fraction of cavitation void as a function of the displacement from the fractured tip of the fractured specimen shown in Figure 8 b).

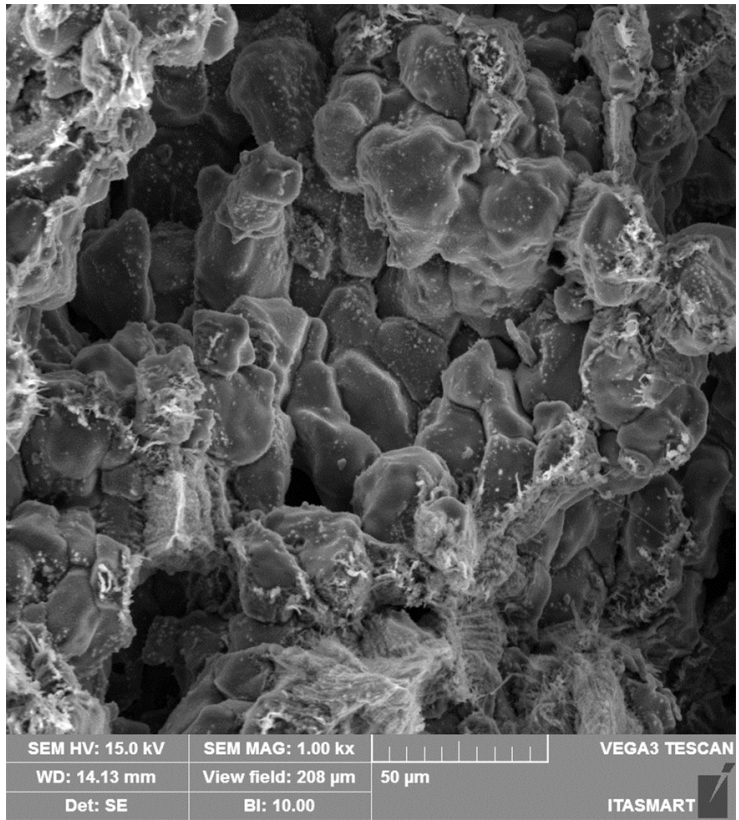

Figure 12. SEM image of the surface fracture of the AA5083-O fractured in the tensile test with a strain rate of $5.10^{-5} \mathrm{~s}^{-1}$ at a temperature of $570^{\circ} \mathrm{C}$.

the dome, as can be seen in Figure 14. While the test with 10 bar of back pressure, the aluminum sheet could reach the upper die at the end of the pressure cycle, with no visible cracks, as observed in Figure $13 \mathrm{~b}$ ).

Figure 15 shows the thickness reduction as a function of $\varphi$ (angle from the pole) at $\theta$ (angle from the rolling direction) equal to $0^{\circ}$ of the produced domes. It can be observed, in both domes, that the thickness reduction decreases as the $\varphi$ increases, it is due to the frictional force that opposes the motion of the part in contact with the die. The dome without back pressure fractured with about $50 \%$ of thickness reduction at $\varphi$ equal to $4.4^{\circ}$, which is consistent with the result of low ductility observed in the tensile test. On the other hand, the blow forming with 10 bar of back pressure was completely conformed with a thickness reduction of $77.2 \%$ at $\varphi$ equal to 3.8 .

Tabela 3. The area of cavitation and test condition for AA 5083.

\begin{tabular}{|c|c|c|c|c|c|c|c|}
\hline \multirow{3}{*}{$\begin{array}{l}\text { Reference } \\
\text { Cavitation area / \% }\end{array}$} & \multicolumn{3}{|c|}{ Tensile test } & \multicolumn{4}{|c|}{ Blow forming } \\
\hline & \multirow{2}{*}{$\begin{array}{c}\text { In this } \\
\text { paper } \\
9\end{array}$} & \multirow{2}{*}{$\begin{array}{l}{\left[{ }^{21}\right]} \\
0.5\end{array}$} & \multirow{2}{*}{$\begin{array}{c}{\left[{ }^{22}\right]} \\
4\end{array}$} & \multicolumn{2}{|c|}{ In this paper } & \multicolumn{2}{|c|}{$\left[{ }^{23}\right]$} \\
\hline & & & & 2.5 & 0.3 & 1.0 & 0,2 \\
\hline Back pressure / $\mathrm{MPa}$ & 0 & 0 & 0 & 0 & 10 & 0 & 2 \\
\hline True Strain & 0.45 & 0.5 & 0.6 & 0.41 & 0.57 & & \\
\hline Temperature $/{ }^{\circ} \mathrm{C}$ & $570^{\circ} \mathrm{C}$ & 550 & 450 & \multicolumn{2}{|c|}{570} & \multicolumn{2}{|c|}{515} \\
\hline Strain rate $/ \mathrm{s}^{-1}$ & $5 \times 10^{-5}$ & $5 \times 10^{-4}$ & $3 \times 10^{-4}$ & \multicolumn{2}{|c|}{$5 \times 10^{-5}$} & \multicolumn{2}{|c|}{$5 \times 10^{-4}$} \\
\hline Grain size / $\mu \mathrm{m}$ & 81 & 7 & 8 & \multicolumn{2}{|c|}{81} & \multicolumn{2}{|c|}{-} \\
\hline Second phase size / $\mu \mathrm{m}$ & 9 & - & 2,56 & \multicolumn{2}{|c|}{9} & \multicolumn{2}{|c|}{-} \\
\hline
\end{tabular}



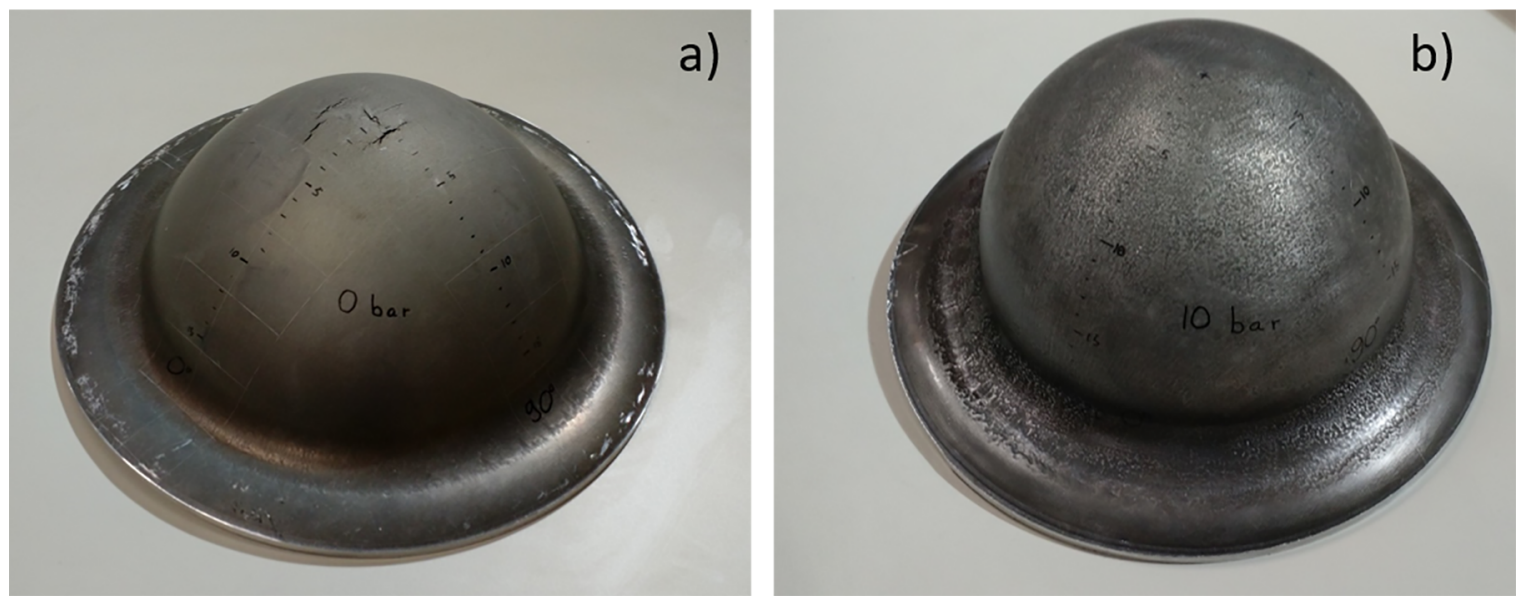

Figure 13. Domes made via blow forming of the coarse-grained AA $5083 \mathrm{O}$ aluminium alloy with: a) no back pressure; and b) 10 bar back pressure.

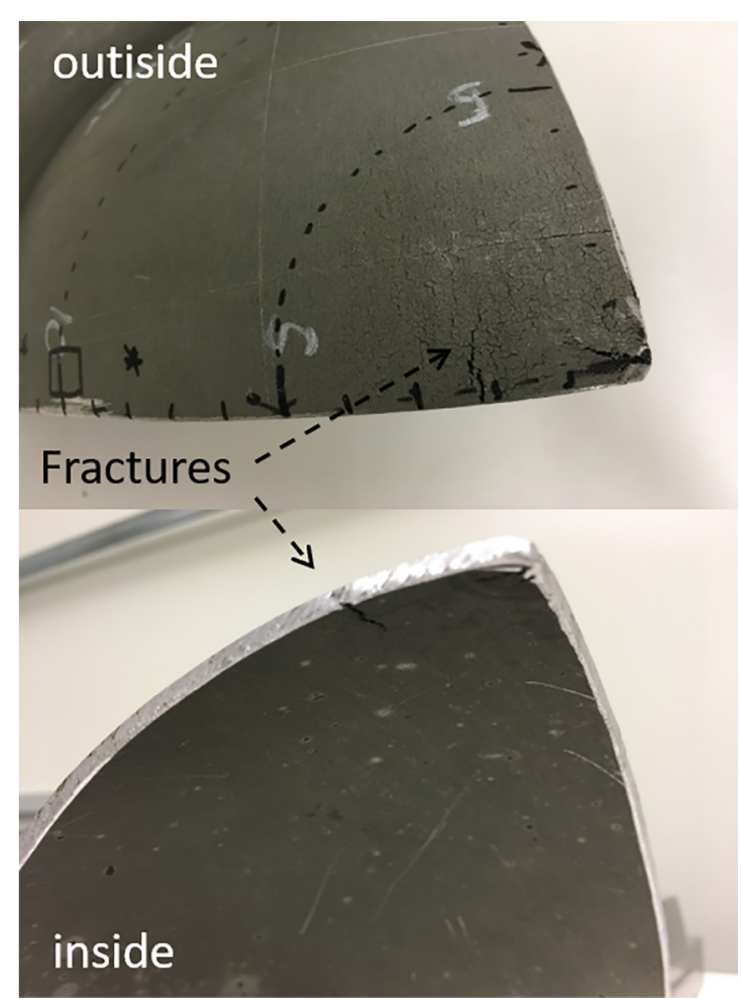

Figure 14. Cross section of the dome performed without back pressure.

Figure 16 shows a void at sample extracted from the positions of $\left(\varphi=45^{\circ} ; \theta=0^{\circ}\right)$ of the dome processed without back-pressure. As presented in the SEM image of Figure 9, the void was formed by interlinkage of neighboring cavitation voids nucleated second phase particles.

Figure 17 shows the microstructures, obtained via SEM, of the sample extracted from the position $\varphi=45^{\circ}$ and $\theta=0^{\circ}$ of the dome without and with 10 bar of back-pressure, as shown in Figure 17 a) and b), respectively. The dome without back pressure presented a high amount of cavitation void area, and the cavitations alignment is predominantly perpendicular to

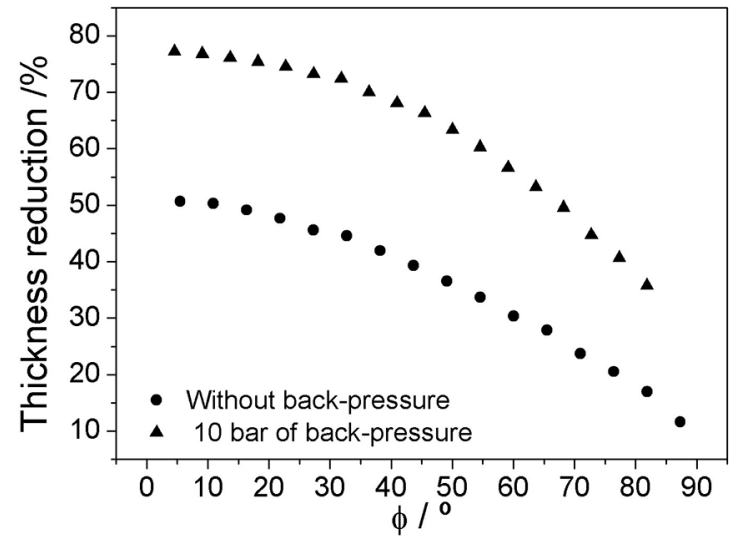

Figure 15. Thickness reduction as a function of $\varphi$ at $\theta$ equal to $0^{\circ}$, of domes produced with and without back-pressure.

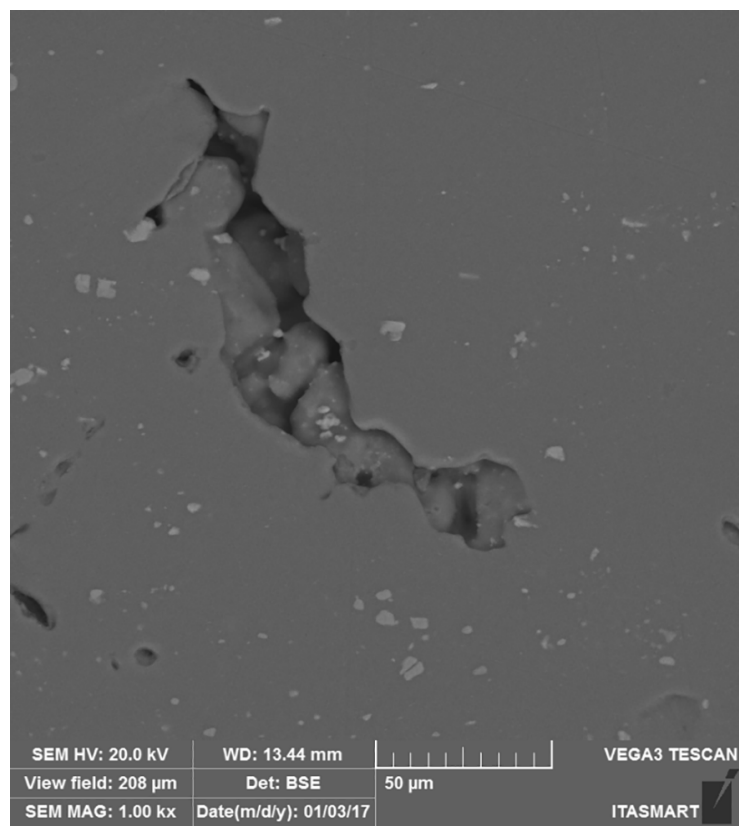

Figure 16. SEM images of domes processed without back-pressure showing the grains inside a void, samples extracted from the positions of $\left(\varphi=45^{\circ} ; \theta=0^{\circ}\right)$. The rolling plane is parallel to the page and the rolling direction is horizontal to the page. 


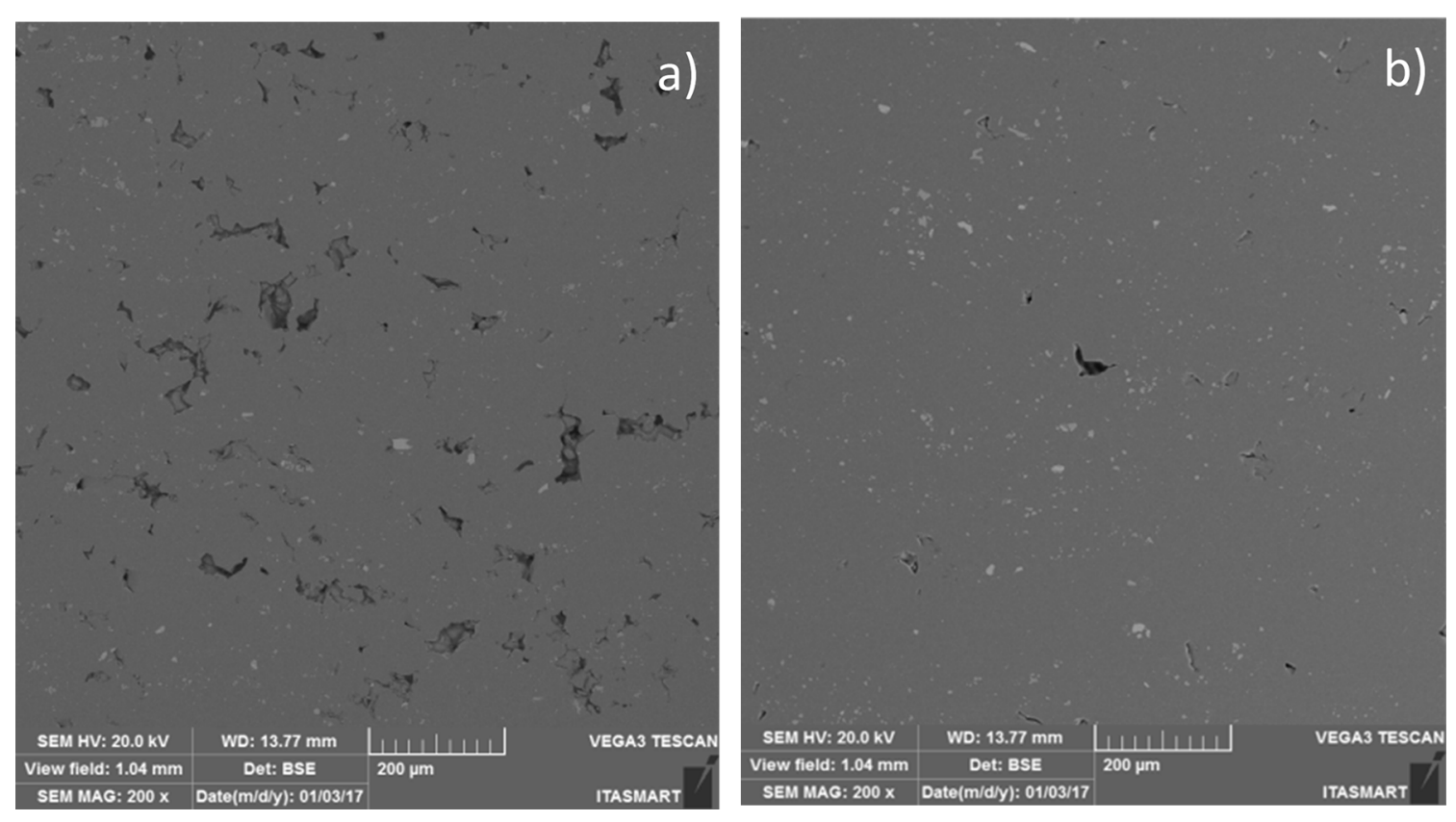

Figure 17. SEM images of domes processed: a) without back-pressure; and b) with 10 bar of back-pressure, samples extracted from the positions of $\left(\varphi=45^{\circ} ; \theta=0^{\circ}\right)$, the rolling plane is parallel to the page and the rolling direction is horizontal to the page.

the stress applied, that is the same as rolling direction for this samples, it corroborates with discussions from Figure 10.

It is clear to see that the area fraction of cavitation voids diminishes significantly with employment of back-pressure. The dome processed without the back-pressure presented area fraction of cavitation voids of about $2.5 \pm 0.2 \%$. The dome with back-pressure presented just $0.3 \pm 0.1 \%$, it is compatible with the literature, as can be seen in Table 3 . This result shows that the use of back pressure is efficient to diminish the quantity of cavitation voids even at very favorable conditions for cavitation growth.

\section{Conclusions}

The aluminum alloy 5083 presented a granular fracture typical in materials deformed by grain boundary sliding. The ultimate true strain was about 0.46 , this low ductility was certainly due to the high area of cavitation voids, about $9 \%$. It was associated with the coarse grain size $(81 \mu \mathrm{m})$ and large second phase particles $(9 \mu \mathrm{m})$ in the alloy microstructure and the high test temperature $\left(570^{\circ} \mathrm{C}\right)$.

In the domes produced by superplastic blow forming, the area of cavitation voids decreased significantly and the thickness reduction increased from $50 \%$ to $77.2 \%$ (limited by the female die) by applying 10 bar of back pressure. It shows the effectiveness of back pressure in diminish the quantity of cavitation voids even at very favorable condition for cavitation growth.

Furthermore, this work can be industrially useful as a database for setup the superplastic blow forming for coarsegrained AA 5083 alloy.

\section{Acknowledgment}

The authors acknowledge FIPT (Fundação de Apoio ao Instituto de Pesquisa Tecnológicas) for the financial support to this research.

\section{References}

1. Padmanabhan KA, Davies GJ. Superplasticity-Mechanical and Structural Aspects, Environmental Effects, Fundamentals and Applications. Volume 1. Berlin, Heidelberg: Springer; 1980. DOI: https://doi.org/10.1007/978-3-642-81456-3

2. Higashi K, Ohnishi T, Nakatani Y. Superplastic behavior of commercial aluminum bronze. Scripta Metallurgica. 1985;19(7):821-823.

3. Langdon TG. Seventy-five years of superplasticity: historic developments and new opportunities. Journal of Materials Science. 2009;44(22):5998.

4. Barnes AJ. Superplastic Forming 40 Years and Still Growing. Journal of Materials Engineering and Performance. 2013;22(10):2935-2949.

5. Dudina DV, Mishra RS, Mukherjee AK. Superplasticity. Reference Module in Materials Science and Materials Engineering. 2016;18. DOI: https://doi.org/10.1016/B978-0-12-803581-8.02886-1

6. Pereira DA, Batalha MHF, Carunchio AF, Resende HB. Analysis of Superplastic Forming Process Applied to Aerospace Industry: Case Study of Al 5083 Alloy. In: Aerospace Technology Congress; 2016 Oct 11-12; Solna, Sweden. Available from: $<\mathrm{https}: / / \mathrm{ftfsweden}$. se/wp-content/uploads/2016/11/FT2016 K01_Daniel_Pereira_full-paper.pdf $>$. 
7. Furushima T, Manabe K. Superplastic micro-tubes fabricated by dieless drawing processes. In: Giuliano G, ed. Superplastic Forming of Advanced Metallic Materials. Cambridge: Woodhead Publishing; 2011. p. 327-360.

8. Lee DN, Lee SB. Abnormal Grain Growth Texture. [Internet]. In: Glebovsky V, ed. Recrystallization in Materials Processing. Rijeka: InTech; 2015. Available from: $<$ http://www.intechopen. com/books/recrystallization-in-materials-processing/abnormalgrain-growth-texture>

9. Shadkam A. A study on the coupled effects of solute and grain size on the work hardening of fine-grained FCC alloys. [Thesis] [Internet]. Vancouver: University of British Columbia; 2014. Available from: $<$ https://open.library.ubc.ca/cIRcle/collections/ ubctheses/24/items/1.0166948>

10. Ramesh KT. Nanomaterials: Mechanics and Mechanisms [Internet]. New York: Springer US; 2009. 316 p. Available from: <http://www.springer.com/la/book/9780387097824>

11. Dutta A, Mukherjee AK. Superplastic forming: an analytical approach. Materials Science and Engineering: A. 1992;157(1):913.

12. Pilling J, Ridley N. Effect of hydrostatic pressure on cavitation in superplastic aluminium alloys. Acta Metallurgica. 1986;34(4):669679.

13. Cleveland RM, Ghosh AK, Bradley JR. Comparison of superplastic behavior in two 5083 aluminum alloys. Materials Science and Engineering: A. 2003;351(1-2):228-236.

14. Livesey DW, Ridley N. Effect of grain size on cavitation in superplastic Zn-Al eutectoid. Journal of Materials Science. 1982;17(8):2257-2266.

15. Verma R, Ghosh AK, Kim S, Kim C. Grain refinement and superplasticity in $5083 \mathrm{Al}$. Materials Science and Engineering: A. 1995;191(1-2):143-150.
16. ASTM International. ASTM B209M-14: Standard Specification for Aluminum and Aluminum-Alloy Sheet and Plate (Metric). West Conshohocken: ASTM International; 2014. DOI: 10.1520/ B0209M-14.

17. Verma R, Friedman PA, Ghosh AK, Kim S, Kim C. Characterization of superplastic deformation behavior of a fine grain $5083 \mathrm{AI}$ alloy sheet. Metallurgical and Materials Transactions A. 1996;27(7):1889-1898.

18. Tsuji N, Shiotsuki K, Saito Y. Superplasticity of Ultra-Fine Grained Al-Mg Alloy Produced by Accumulative Roll-Bonding. Materials Transactions. 1999;40(8):765-771.

19. Park KT, Hwang DY, Chang SY, Shin DH. Low-temperature superplastic behavior of a submicrometer-grained $5083 \mathrm{Al}$ alloy fabricated by severe plastic deformation. Metallurgical and Materials Transactions A. 2002;33(9):2859-2867.

20. Chokshi AH, Langdon TG. The nucleation and growth of cavities in a superplastic quasi-single phase copper alloy. Acta Metallurgica et Materialia. 1990;38(5):867-877.

21. Chan KC, Chow KK. Analysis of hot limit strains of a superplastic 5083 aluminum alloy under biaxial tension. International Journal of Mechanical Sciences. 2002;44(7):1467-1478.

22. Kulas MA, Green WP, Taleff EM, Krajewski PE, McNelley TR. Failure mechanisms in superplastic AA5083 materials. Metallurgical and Materials Transactions A . 2006;37(3):645655.

23. Chen ZP, Thomson PF. A study of post-form static and fatigue properties of superplastic 7475-SPF and 5083-SPF aluminium alloys. Journal of Materials Processing Technology. 2004;148(2):204-219.

24. Shei SA, Langdon TG. The fracture characteristics of a superplastic single phase copper alloy. Journal of Materials Science. 1978;13(5):1084-1092. 